Bull. Mater. Sci., Vol. 35, No. 4, August 2012, pp. 513-517. (C) Indian Academy of Sciences.

\title{
Morphological and compositional engineering of Ni/carbon nanotube composite film via a novel cyclic voltammetric route
}

\author{
YU JUN YANG \\ School of Chemistry and Chemical Engineering, Xuchang University, Xuchang, China
}

MS received 9 January 2011; revised 8 June 2011

\begin{abstract}
Ni/multi-walled carbon nanotubes (MWCNTs) composite films were deposited on the glassy carbon electrode (GCE) by a Ni plating bath containing homogeneously dispersed MWCNTs using polyvinylpyrrolidone (PVP) as dispersion additive. Incorporation of MWCNTs into Ni matrix was greatly enhanced by the application of cyclic voltammetric (CV) deposition technique. The structure and nature of the Ni/MWCNT were characterized by field emission scanning electron microscope (FE-SEM) and X-ray diffraction (XRD). The results show that the content of MWCNT and the morphology of the deposited Ni/MWCNT composite film can be controlled by selecting the appropriate electroplating conditions. Further study indicates that the obtained Ni/MWCNT showed excellent electro-catalytic activity for the oxidation of ethanol in alkaline solution.
\end{abstract}

Keywords. Carbon nanotubes; cyclic voltammetry; electrodeposition; nickle; composite.

\section{Introduction}

Nickel is an effective and cheap catalyst for oxidation of small organic compounds including glucose (Huang 2009), carbohydrates (Ojani et al 2004, 2008), especially, methanol (El-Shafei 1999; Golikand et al 2006; Jin et al 2009) and ethanol (Weng et al 2004; Basu et al 2008; Singh et al 2009). For example, nickel redox centres, $\mathrm{Ni}(\mathrm{OH})_{2} / \mathrm{NiOOH}$, formed on the nickel surface show high catalytic activity towards the oxidation of ethanol in alkaline media which possibly undergo competition between two electrons to the aldehyde and four electrons to carboxylic acid (Weng et al 2004; Basu et al 2008; Singh et al 2009). On the other hand, MWCNT is an outstanding catalyst support due to its excellent mechanical characteristics, nanometer size and high surface area (Rao et al 2003; Ajayan and Tour 2007). Thus, a MWCNT and Ni composite (Ni/MWCNT) are expected to be a promising new catalyst material. The Ni/MWCNT can be produced by electrodeposition (Arai et al 2004), electroless deposition (Wang et al 2005) or pyrolysis (Kichambare et al 2002). Among these, electro-synthesis could be a better method due to its convenience and economy.

While many studies have focused on the improvement of the uniform Ni/MWCNT composite film, the ability to synthesize Ni/MWCNT composite film with predictable morphology and composition remains a challenge. The control of surface morphology of the composite film, in addition to the sizes of the nickel crystals in the composite and nickel-toMWCNT ratio, provides one more key factor to manipulate the properties of thin composite film. For future applications of the Ni/MWCNT nanocomposite film, it is foreseen that

(yangyujun@yahoo.com) the control of the morphology as well as the composition will become an important issue.

The present study has tried to develop a novel cyclic voltammetric procedure for an ideal electrodeposition of Ni/MWCNT composite film on GCE. The focus of this experiment is to make the engineering of the surface morphology of the Ni/MWCNT composite and adjustment of the content of carbon nanotubes in the composites possibly by varying the experimental conditions. Firstly, we employed PVP as the dispersing agent to prevent the aggregation of carbon nanotubes in the aqueous electrolyte. Subsequently, we designed a cyclic voltammetric $(\mathrm{CV})$ process to prepare the $\mathrm{Ni} / \mathrm{MWCNT}$ composites. Compared to that prepared with the direct current (DC) technique (Arai et al 2004), Ni/MWCNT formed with $\mathrm{CV}$ technique is more uniform and compact in appearance due to much smaller particle size.

\section{Experimental}

MWCNTs were typically $30-50 \mathrm{~nm}$ in diameter. MWCNTs were synthesized by a chemical vapour deposition method and purified by refluxing in $2.6 \mathrm{~mol} / \mathrm{L} \mathrm{HNO}_{3}$ for $48 \mathrm{~h}$ before use to remove the trace amount of impurities. As-prepared MWCNTs products were purified by immersing them into concentrated nitric acid and hydrofluoric acid in turn, then filtered and washed with deionized water and dried at $120^{\circ} \mathrm{C}$. Prepared $100 \mathrm{~mL}$ electrolyte containing $0.07 \mathrm{M} \mathrm{NiSO}_{4}$ and $0 \cdot 1 \mathrm{M} \mathrm{NaCl}$ which was adjusted to $\mathrm{pH} 3 \cdot 0.2 .5 \mathrm{mg}$ purified MWCNTs and $0.2555 \mathrm{~g}$ PVP were added into $5 \mathrm{~mL}$ electrolyte and dispersed under sonication. A three-electrode electrolytic cell was employed for electrodeposition and electrochemical tests. A GCE (3 mm diameter) was used as 
the cathode. A platinum wire was used as a counter electrode. The saturated calomel electrode (SCE) was used as a reference electrode. Ni/MWCNT composite deposition was carried out by potential scanning from $0 \mathrm{~V}$ to $-1.5 \mathrm{~V}$ (vs SCE) in a deaerated electrolyte. The scan rates were 5, 10, $15 \mathrm{mV} / \mathrm{s}$, respectively.

Powder X-ray diffraction (XRD) data were collected using a Siemens X-ray diffractometer at a scanning rate of $4 \% \mathrm{~min}$ (step size is $0.02^{\circ}$ and count time/step is $0.3 \mathrm{~s}$ ) in the $2 \theta$ range from $10^{\circ}-80^{\circ}$, with graphite monochromatized $\mathrm{Cu} \mathrm{K} \alpha$ radiation $(\lambda=1.54056 \AA)$. Morphology study of the films on the GCE surface was carried out with a Quanta 200 scanning electron microscope (SEM; FEI Company, Holland). The electrochemical tests were carried out with a CHI 830 potentiostat (Chen Hua Company, China).

\section{Results and discussion}

Electrochemical and electrophoretic methods have been used in the polarization, orientation and deposition of MWCNTs (Kamat et al 2004; Samant et al 2007). In this experiment, the oxidatively shortened and $-\mathrm{COOH}$ functionalized multiwalled carbon nanotubes were prepared by refluxing MWCNT in nitric acid. In the solution, $\mathrm{Ni}^{2+}$ reacted with MWCNT- $\left(\mathrm{COO}^{-}\right)_{n}$ to form positively charged NiMWCNTs, which migrated towards the GCE cathode and deposited on the cathode surface under d.c. electric field while the $\mathrm{Ni}^{2+}$ cations on the MWCNT surface and in the vicinity of cathode were reduced due to good conductivity of MWCNTs.

To synthesize the metal/carbon nanotube composites by electrodeposition, it would be indispensable to uniformly disperse carbon nanotubes in the aqueous electrolyte, thus achieve the incorporation of carbon nanotubes into the composites. However, carbon nanotubes have a propensity to aggregate into packed ropes or entangled networks due to strong inter-tubes van der Waals attraction. Thus, selecting an appropriate dispersing additive is crucial for deposition of Ni/MWCNT composite. Our study has discovered that PVP is more effective for MWCNT dispersion than tetraoctyl ammomium bromide (TOAB) (Kamat et al 2004), hexadecyltrimethylammonium bromide (CTAB) (Jiang et al 2008), sodium dodecyl sulfate (SDS) (Islam et al 2003) and hydroxypropylcellulose (HPC) (Yang et al 2008). The electrolyte containing PVP is highly stable and no precipitate is observed even after one month.

It was found that carbon nanotubes can be easily solubilized in water by non-covalently wrapping them with a variety of linear polymers such as PVP and polystyrene sulfonate (PSS) (O'Connell et al 2001). The surface $\mathrm{p} K$ a value of PVP was detected from the derivative of the curves of the contact angle $(d \theta / d \mathrm{pH})$ vs $\mathrm{pH}$. The $\mathrm{p} K$ a value of the pyridyl groups on PVP chains was found to be 7.5 (Demirci et al 2009). In this experiment, the MWCNTs were modified with PVP and the pyridyl groups on the PVP chains were protonated and positively charged subsequently in $\mathrm{pH} 3$ aqueous solution. Thus, the PVP-wrapped MWCNTs (PVPMWCNT) were positively charged colloids (Bocharova et al 2006). The feasible PVP-MWCNTs dispersion in aqueous solution and the improved stability of their suspension were attributed to the strong electrostatic repulsion between the protonated PVP-MWCNTs.

Electrodeposition behaviour of Ni/MWCNT composites were examined with variations of experimental parameters such as scan rates, number of scan cycles, the concentration of MWCNTs and the application of electrolyte stirring. Figure 1 shows SEM photographs of electrodeposits formed at different scan rates without stirring. Scan range was from 0 to $-1.5 \mathrm{~V}$. The number of scan cycles is 5,10 and 15 for experiments carried out at 5,10 and $15 \mathrm{mVs}^{-1}$, respectively to maintain a constant deposition time. At $5 \mathrm{mVs}^{-1}$, irregularly shaped nickel crystal aggregates together and the carbon nanotubes distributed sparsely in the composite film (figure 1(a)). As shown in figure 1(b), at $10 \mathrm{mVs}^{-1}$, the spherical Ni crystals with a diameter of about $200 \mathrm{~nm}$ assembled separately along the carbon nanotubes. Similar phenomenon has been observed by Arai et al (2004). It is probably more preferable for the Ni nanoparticles to form at the local defects and end of MWCNT as a lot of irregular or spherical aggregate islands. Compared to the Ni/MWCNT composite obtained at $10 \mathrm{mVs}^{-1}$, aggregation of the Ni crystals in figure 1(c) is much more serious although the average diameter of the $\mathrm{Ni}$ crystals obtained at $15 \mathrm{mVs}^{-1}$ is only $74 \mathrm{~nm}$.

Figure 2 illustrates surface morphologies of the Ni/ MWCNT composites electrodeposited at different concentrations of MWCNT in the electrolytic cell without stirring.

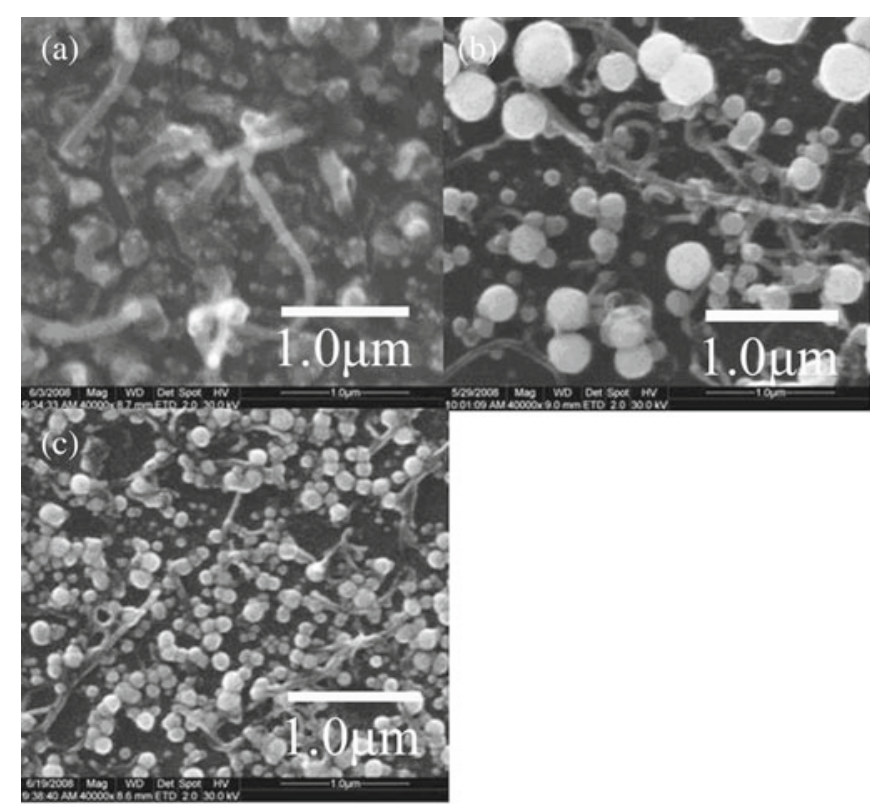

Figure 1. Morphology of composite film obtained in $5 \mathrm{~mL}$ deposition bath (pH 3, 0.1 M NaCl, 0.07 $\mathrm{M} \mathrm{NiSO}_{4}, 0.5 \mathrm{mg} / \mathrm{mL}$ MWCNT and $0.0511 \mathrm{~g} / \mathrm{mL}$ PVP) by cycling from 0 to $-1.5 \mathrm{~V}$ at scan rates of 5 (a), 10 (b), and $15 \mathrm{mVs}^{-1}$ (c) for 5, 10 and 15 cycles without stirring. 

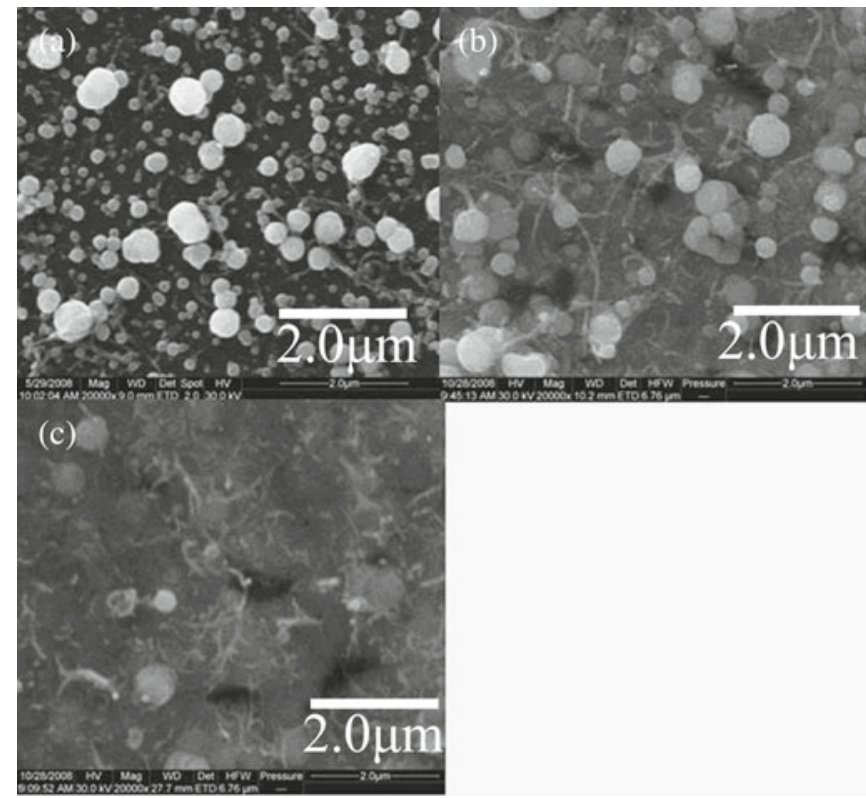

Figure 2. Morphology of composite film obtained in $5 \mathrm{~mL}$ deposition bath (pH 3, 0.1 M NaCl, 0.07 $\mathrm{M} \mathrm{NiSO}_{4}, 0.5$ (a), 0.8 (b) and $1.4 \mathrm{mg} / \mathrm{mL}$ (c) MWCNT and $0.0511 \mathrm{~g} / \mathrm{mL}$ PVP) by cycling from 0 to $-1.5 \mathrm{~V}$ at a scan rate of $10 \mathrm{mVs}^{-1}$ for 10 cycles without stirring.

As shown in figures 2(a), (b) and (c), amount of MWCNTs in the composite film deposited on GCE cathode apparently increased with increasing concentration of MWCNT from $0.5-0.8$ and $1.4 \mathrm{mg} / \mathrm{mL}$ in the electrolytic cell. From the results mentioned above it can be recognized that the concentration of MWCNTs plays an important role in the preparation of composite of Ni and MWCNTs by electrodeposition. With the increase of concentration of MWCNTs, more MWCNTs can be deposited on the surface of the cathode and their coverage on the cathode also increases. When the concentration of MWCNTs was increased to cover the whole surface of the cathode, the current can be distributed more uniformly, and thus Ni can be more uniformly deposited on the surface of MWCNTs to form the composite. However, MWCNTs are easy to agglomerate in aqueous solution. Higher MWCNTs concentration will enhance the agglomeration of MWCNTs in the electrolytic cell, which results in difficulty of deposition and coverage of MWCNTs on the cathode. Hence there should be an excess amount of PVP dispersing additive in the electrolyte to prevent the aggregation of MWCNTs.

Figure 3 shows SEM photographs of electrodeposits formed at different scan cycles without stirring, in other words, different deposition times while other experimental conditions remain constant. The density of Ni nanocrystals increases as the number of scan cycles is increased from 10 (a) to 15 (b), 20 (c) and 30 (d) cycles.

The effect of stirring was also investigated. Figure 4 shows SEM photographs of electrodeposits formed at different scan rates under stirring. After comparing figure 2 with figure 4, the result clearly indicates that the employment of stirring significantly enhances the incorporation of carbon nanotubes

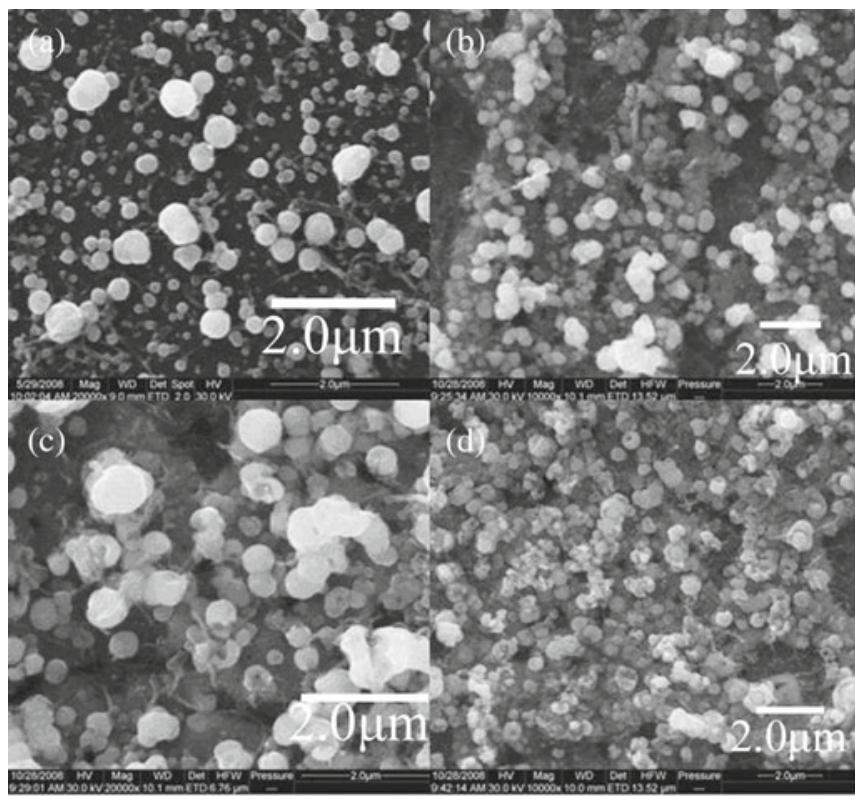

Figure 3. Morphology of composite film obtained in $5 \mathrm{~mL}$ deposition bath ( $\mathrm{pH} 3,0.1 \mathrm{M} \mathrm{NaCl}, 0.07 \mathrm{M} \mathrm{NiSO}_{4}, 0.5 \mathrm{mg} / \mathrm{mL}$ MWCNT and $0.0511 \mathrm{~g} / \mathrm{mL}$ PVP) by cycling from 0 to $-1.5 \mathrm{~V}$ at a scan rate of $10 \mathrm{mVs}^{-1}$ for 10 (a), 15 (b), 20 (c) and 30 (d) cycles without stirring.
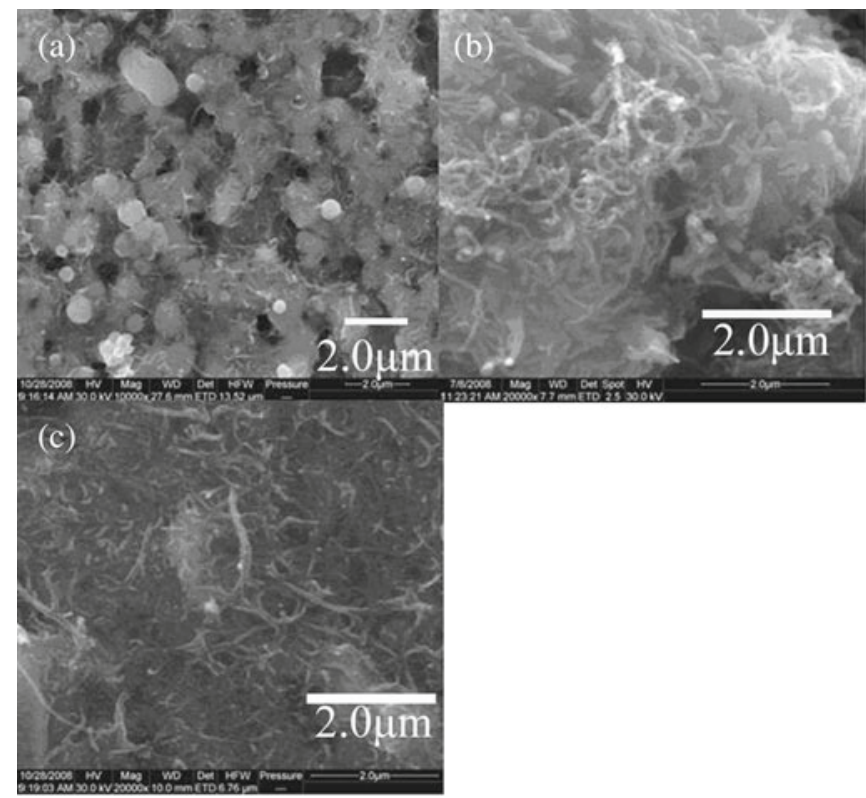

Figure 4. Morphology of the composite film obtained in $5 \mathrm{~mL}$ deposition bath ( $\mathrm{pH} 3,0.1 \mathrm{M} \mathrm{NaCl}, 0.07 \mathrm{M} \mathrm{NiSO}_{4}, 0.5 \mathrm{mg} / \mathrm{mL}$ MWCNT and $0.0511 \mathrm{~g} / \mathrm{mL}$ PVP) by cycling from 0 to $-1.5 \mathrm{~V}$ at scan rate of $5(\mathrm{a}), 10$ (b) and $15 \mathrm{mVs}^{-1}$ (c) for 5, 10 and 15 cycles under stirring.

into the composite films. As shown in figure 4, it is very obvious that a more homogeneous coating was formed when the scan rate was raised from $5 \mathrm{mVs}^{-1}$ to $15 \mathrm{mVs}^{-1}$.

Figure 5 shows SEM photographs of electrodeposits formed at different concentrations of MWCNT in the 


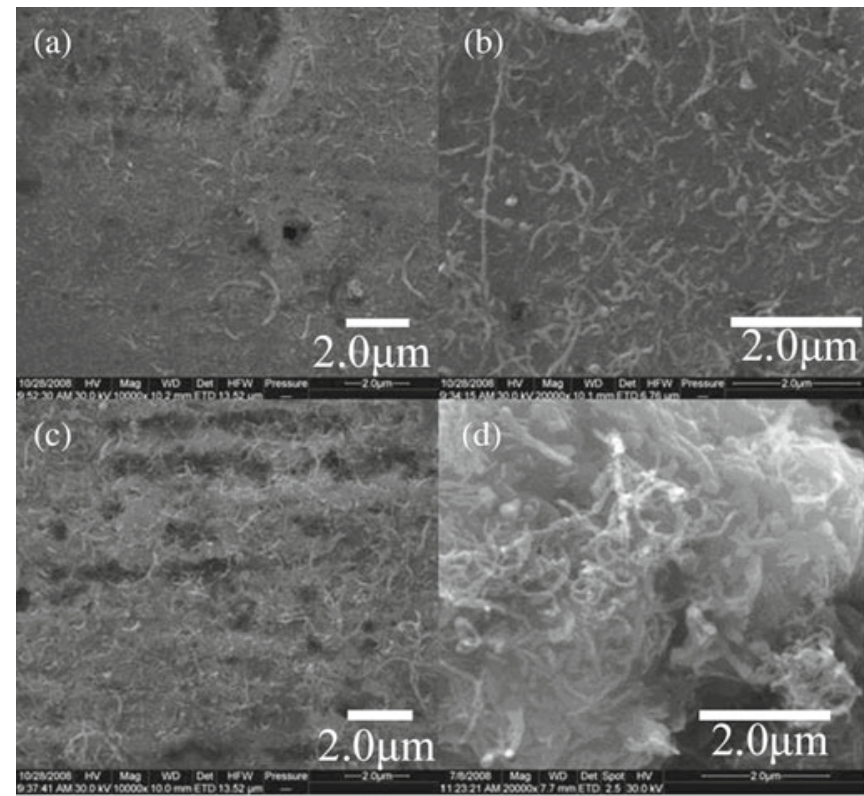

Figure 5. Morphology of composite film obtained in $5 \mathrm{~mL}$ depo-

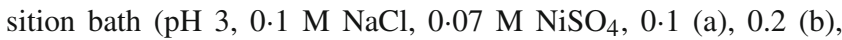
0.3 (c), and $0.5 \mathrm{mg} / \mathrm{mL}$ (d) MWCNT and $0.0511 \mathrm{~g} / \mathrm{mL} \mathrm{PVP)} \mathrm{by}$ cycling from 0 to $-1.5 \mathrm{~V}$ at a scan rate of $10 \mathrm{mVs}^{-1}$ for 10 cycles under stirring.

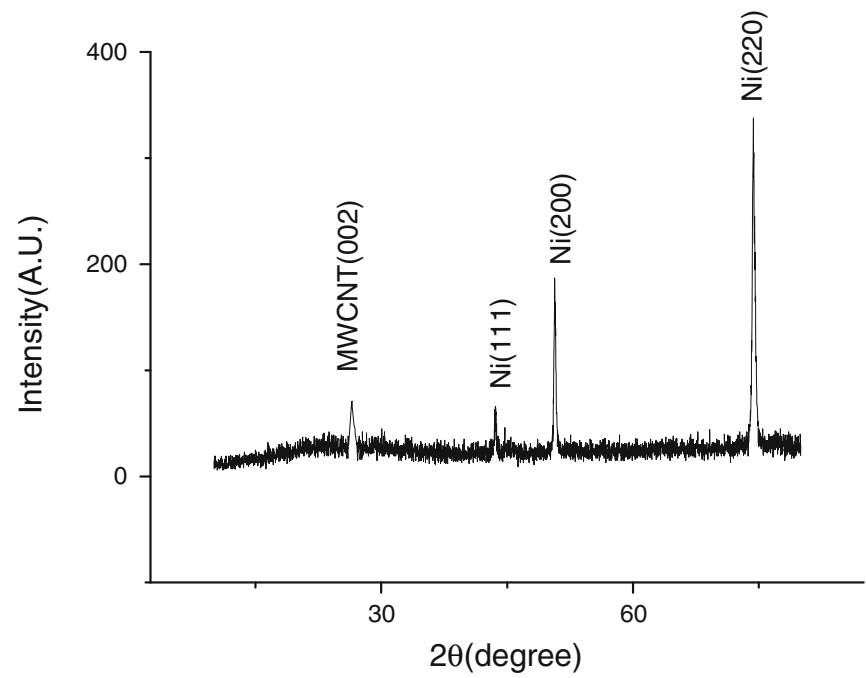

Figure 6. XRD pattern of Ni/MWCNT composite with cyclic voltammetric deposition in $5 \mathrm{~mL}$ deposition bath $(\mathrm{pH} \mathrm{3,0.1} \mathrm{M}$ $\mathrm{NaCl}, 0.07 \mathrm{M} \mathrm{NiSO}_{4}, 0.5 \mathrm{mg} / \mathrm{mL}$ MWCNT and $0.0511 \mathrm{~g} / \mathrm{mL}$ PVP) by cycling from 0 to $-1.5 \mathrm{~V}$ at a scan rate of $10 \mathrm{mVs}^{-1}$ for 10 cycles under stirring.

electrolytic cell under stirring. Without stirring, the density of MWCNTs increased apparently with the increasing concentration of MWCNT in the electrolyte (figure 2). However, no obvious change of density of MWCNTs in the composite film is observed when stirring was applied (figure 4). A homogeneous coating was formed in the cell with lower MWCNTs concentration, but the surface became coarser when MWCNTs concentration was raised. This may

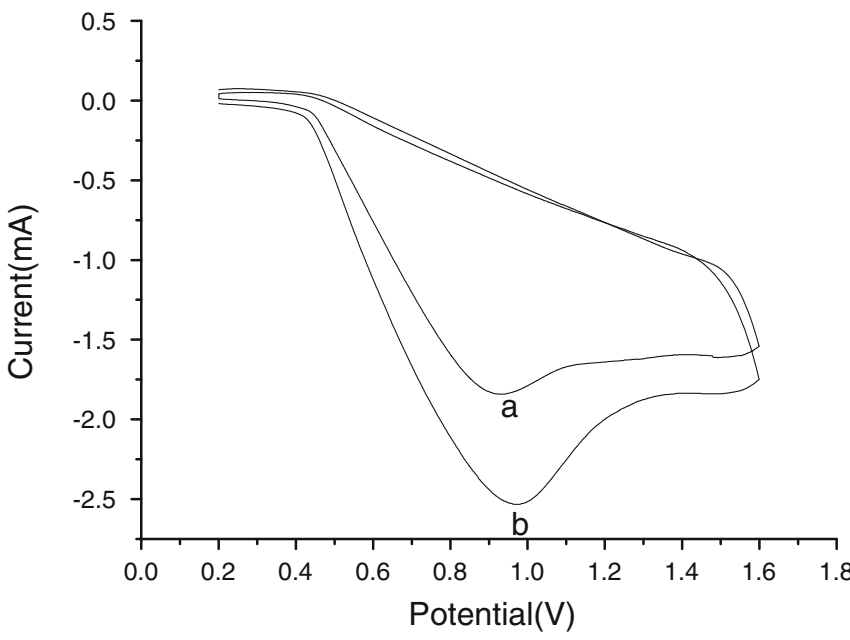

Figure 7. $\mathrm{CVs}$ of $0.03 \mathrm{M} \mathrm{C}_{2} \mathrm{H}_{5} \mathrm{OH}$ in $0.1 \mathrm{M} \mathrm{NaOH}$ at $\mathrm{Ni} /$

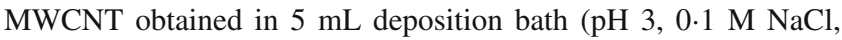
$0.07 \mathrm{M} \mathrm{NiSO}_{4}, 0.5 \mathrm{mg} / \mathrm{mL}$ MWCNT and $0.0511 \mathrm{~g} / \mathrm{mL} \mathrm{PVP)} \mathrm{by}$ cycling from 0 to $1.5 \mathrm{~V}$ at scan rate of $10 \mathrm{mVs}^{-1}$ for 10 cycles without stirring (a) or under stirring (b) (scan: $100 \mathrm{mVs}^{-1}$ ).

be due to the agglomerative effect of MWCNTs in the coatings since MWCNTs content in the co-deposited coatings increased with the increase of MWCNTs concentration in the electrolytic cell.

Figure 6 shows X-ray diffraction patterns taken from the Ni/MWCNT composites deposited on glassy carbon substrates. It can be seen that a diffraction peak from the (002) plane of carbon nanotubes is observed at $2 \theta=26.4^{\circ}$ together with three peaks at $2 \theta=44.5^{\circ}, 51.8^{\circ}$ and $74.7^{\circ}$,

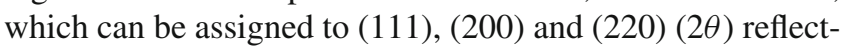
ion of face-centred cubic Ni crystals. This result confirms co-existence of carbon nanotubes and $\mathrm{Ni}$, being in good agreement with SEM results. As can be seen from figure 4(b), the fibre shaped products formed on the cathode consists of Ni and MWCNTs. Therefore, it can be deduced that Ni deposit layer has been formed on the surface of MWCNTs. The fibre shaped products comprise of a Ni outer layer and an inner MWCNTs covered with Ni layer, viz. a composite of MWCNTs coated with Ni.

Figure 7 shows $\mathrm{CVs}$ of $0.03 \mathrm{M} \mathrm{C}_{2} \mathrm{H}_{5} \mathrm{OH}$ at Ni/MWCNT in $0.1 \mathrm{M} \mathrm{NaOH}$. It can be readily seen that the Ni/MWCNT shows an excellent electrocatalytic oxidation of $\mathrm{C}_{2} \mathrm{H}_{5} \mathrm{OH}$ with a sharply increasing peak current and negative potential. The oxidation of ethanol undergoes two processes, one corresponds to the formation of $\mathrm{Ni}(\mathrm{III})$ species with a reversible transformation of $\mathrm{Ni}(\mathrm{OH})_{2} / \mathrm{NiOOH}$. The other is only $\mathrm{Ni}(\mathrm{III})$ species $(\mathrm{NiOOH})$ produced at the electrode surface, and a new anodic peak with a large peak current formed in the presence of ethanol. This suggests that ethanol is oxidized and accompanied by the transformation of $\mathrm{NiOOH}$ to $\mathrm{Ni}(\mathrm{OH})_{2}$ (Weng et al 2004; Basu et al 2008; Singh et al 2009). Therefore, NiOOH probably acts as an electrocatalyst (Basu et al 2008). Figure 7 also indicates that the Ni/MWCNTs obtained under different experimental conditions show different catalytic effects upon 
oxidation of ethanol. In figure 1(b), content of MWCNT in the composite is low and $\mathrm{Ni}$ nanoparticles form at defects and ends of MWCNT resulting in a gathering effect. However, figure 4(b) shows that the external walls of MWCNT were homogeneously coated by $\mathrm{Ni}$ thin film and no aggregate of $\mathrm{Ni}$ crystals can be observed. Comparing figure 1(b) and 4(b) indicates that, under stirring, content of MWCNTs in the composite film is much higher and the formation of $\mathrm{Ni}$ on MWCNTs is more homogeneous than those without stirring. Thus, it is not surprising to find out that the Ni/MWCNT obtained under stirring shows better catalytic effect (figure $7 \mathrm{~b}$ ) than that obtained without stirring (figure 7a) towards the electro-oxidation of ethanol.

\section{Conclusions}

A novel cyclic voltammetric method for preparing $\mathrm{Ni} / \mathrm{MWCNT}$ composite film is proposed. FE-SEM reveals that the composition and morphology of the composite film can be readily adjusted by varying the experimental parameters such as scan rate, potential scan cycles, concentration of MWCNT and application of stirring. Preliminary tests indicated that the Ni/MWCNT composite exhibits a high catalytic activity for the electro-oxidation of ethanol. This simple deposition technique is not limited to Ni but may be used to prepare a variety of metal/MWCNT composite with various metal-to-MWCNT ratios and morphology through similar routines for application as catalysts in fuel cells.

\section{Acknowledgement}

The authors acknowledge financial support by the National Nature Science Foundation of China (Nos. 30770549, 20805035 and 90817103).

\section{References}

Ajayan P M and Tour J M 2007 Nature 4471066

Arai S, Endo M and Kaneko N 2004 Carbon 42641

Basu S, Agarwal A and Pramanik H 2008 Electrochem. Commun. 101254

Bocharova V, Kiriy A, Oertel U, Stamm M, Stoffelbach F and Jerome R 2006 J. Phys. Chem. B110 14640

Demirci S, Alaslan A and Caykara T 2009 Appl. Surf. Sci. 255 5979

El-Shafei A A 1999 J. Electroanal. Chem. 47189

Golikand A N, Asgari M, Maragheh M G and Shahrokhian S 2006 J. Electroanal. Chem. $\mathbf{5 8 8} 155$

Huang J F 2009 Chem. Commun. 101270

Islam M F, Rojas E and Bergey D M 2003 Nano Lett. 3269

Jiang M J, Dang Z M, Yao S H and Bai J B 2008 Chem. Phys. Lett. 457352

Jin G P, Baron R, Rees N V, Xiao L and Compton R G 2009 New J. Chem. 33107

Kamat P V, Thomas K G, Barazzouk S, Girishkumar G, Vinodgopal K and Meisel D 2004 J. Am. Chem. Soc. 12610757

Kichambare P D, Qian D, Dickey E C and Grimes C A 2002 Carbon 401903

O'Connell M J, Boul P, Ericson L M, Huffman C, Wang Y and Haroz E 2001 Chem. Phys. Lett. 342265

Ojani R, Raoof J B and Salmany-Afagh P 2004 J. Electroanal. Chem. 5711

Ojani R, Raoof J B and Fathi S 2008 Electroanal. 201825

Rao S G, Huang L, Setyawan W and Hong S H 2003 Nature 425 36

Samant K M, Chaudhari V R, Kapoor S and Haram S K 2007 Carbon 452126

Singh R N, Singh A and Anindita 2009 Carbon 47271

Wang F, Arai S and Endo M 2005 Carbon 431716

Weng Y C, Rick J F and Chou T C 2004 Biosensors Bioelectron. 2041

Yang Q, Shuai L, Zhou J, Lu F and Pan X 2008 J. Phys Chem. B112 12934 